\title{
Flipped classroom improves results in pathophysiology learning: results of a non- randomised controlled study.
}

\section{J. Ignacio Herrero ( $\square$ iherrero@unav.es )}

Clinica Universidad de Navarra https://orcid.org/0000-0002-9076-6717

Jorge Quiroga

Clinica Universidad de Navarra

\section{Research article}

Keywords: Medical Education Research, Flipped classroom, Pathophysiology, Gender

Posted Date: September 25th, 2019

DOI: https://doi.org/10.21203/rs.2.9889/v3

License: (c) (1) This work is licensed under a Creative Commons Attribution 4.0 International License.

Read Full License 


\section{Abstract}

Background. The flipped classroom has become increasingly popular in health professions education. The aim of this study was to analyse its effect on learning in a pathophysiology course. Methods. Flipped classroom was introduced to teach respiratory pathophysiology in 2018. We compared exam results with the results the previous year and with the exam results from blood pathophysiology from both years (taught by the same teacher, in a traditional way). Groups were compared with the Student's T test. Students answered a survey after finishing the term. Results. 201 students were examined in 2018 (and 229 in 2017). Gender distribution and the qualifications obtained in general pathology were comparable in both years. The results in respiratory pathophysiology were significantly better in 2018 than in 2017 (mean: 48 versus 42 out of 100; $\mathrm{P}=0.004$ ), but the results in blood pathophysiology remained similar. The improvement was significant only in students that scored below the median (mean: 40 versus 33; $P=0.009$ ) and was more evident in male than in female students (mean: 52 versus 44; $P=0.010$ ) and in those who had the same age as (were not older than) the rest of their classmates (mean 51 versus 44; $\mathrm{P}=0.002$ ). Most students considered that flipped classroom was more attractive and helped them to learn more and with less effort. Conclusions. Flipped classroom increases medical students' knowledge acquisitions in pathophysiology. It is more beneficial to male students and those with lower qualifications without academic delay.

\section{Background}

The flipped classroom (FC) is a student-centred pedagogical approach that is becoming increasingly popular in education in the health professions. It switches the traditional order of learning,which is initiated by a didactic lecture (when the teacher exposes the didactic material) and is followed by personal study. In the FC model, students receive the didactic material outside the classroom and discuss with their teacher during the formal teaching time. This approach increases active learning (1). It is aimed to help the students become critical thinkers and stimulate a deep understanding (2).

The potential effect of FC on learning and on students' satisfaction in health professions education has been examined. Two recent meta-analysis have reviewed published studies, with different conclusions. Hew and Lo (3) reviewed the experience in health professions concluding that FC improves learning and is preferred by the students. In contrast, Gillette et al. (4) concluded that FC was associated with minimal gains in students' knowledge compared to lecturing in pharmacy education. A systematic review of the effectiveness of FC in medical education published in 2017 concluded that students were generally satisfied with the FC approach which improved their attitude, but changes in knowledge and skill bore mixed results. Some studies revealed positive findings, but others found minimal differences between FC and the traditional lecturing approach (5).

Thus, the aim of this manuscript was to report our initial experience with FC in the teaching of pathophysiology to third-year medical students. 
Conceptual framework

Teaching pathophysiology in a large group (more than 200 learners) is usually based on didactic lectures. As active learning improves students' performance (6) we decided to introduce active teaching in form of FC and to test its effects. The results of this method of active learning may depend on individual characteristics. Our main objective was to improve the learning of all students, mainly of those with worse performance. Thus, we studied the effect according to their gender and their previous academic results.

\section{Materials And Methods}

\section{Participants and settings}

The medical curriculum in the Universidad de Navarra consists of six years (three pre-clinical and three clinical years). The curriculum is based on the achievement of competences. Participants were third-year medical students from the Universidad de Navarra (Pamplona, Spain) in two consecutive years (219 in 2017-18 and 201 in 2018-19) who were enrolled in the pathophysiology course. Pathophysiology is a whole-year course divided in two four-month semesters. The first semester (September to December) includes cardiovascular, renal, respiratory and blood pathophysiology and the second semester (January to April) includes neurological, endocrine, metabolic and liver and gastrointestinal pathophysiology. The teachers of this subject are members of the department of internal medicine. In the first semester, one of the staff members (JIH) teaches both respiratory (RP) and blood pathophysiology (BP). At the end of the first semester, in December, the students sit an exam. Those who score 60 or more out of 100 do not need to be examined for this particular topic in the final exam in May. This exam includes a test with 100 multiple-choice questions ( 25 of every of the four parts). The final score is obtained after subtracting one third of the number from wrong answers to the number of correct answers.

\section{$\underline{\text { Intervention }}$}

In 2018, a FC method was used to teach RP. Several days before each session, the students received 3-4 videos of 5-7 minutes for each lesson. The videos consisted of the same slides given in the 2017 lectures (that were given as a didactic lecture) and an audio that was recorded for 2018. The students were allowed to send an e-mail to the teacher asking for a more detailed explanation of the doubtful points. The schema for the subsequent 45 to 50 -minute session was: 1) a 5-minute review of the lesson explained in the last session through 3-4 multiple-choice questions using the app Socrative (www.socrative.com); 2) explanation of the students' questions (sent via e-mail or asked in the classroom) and the most important / difficult concepts according to the teacher's criterion (20-30 minutes); 3) presentation and discussion of a brief clinical case (5-10 minutes); and 4) review of the lesson commenting the respective multiple-choice questions included in the previous year's exam. 
For the traditional approach, the same teacher taught BP, without using videos. The schema of the sessions was similar, but the lesson of the day was explained in a didactic lecture. The students received the slides several days before the session. In 2017, the same teacher had taught RP and BP, but both were given as a didactic lecture. The results of that year were used as control.

The staff members of the department of internal medicine were also the teachers of general pathology (GP) in the second year. This four-month course is an introduction to pathophysiology and is mostly devoted to the explanation of etiology and pathogenesis of disease.

We studied whether the potential improvement in the results with the flipped learning were related to age, gender and/or previous academic performance, as measured by the results obtained in general pathology (above / below the median).

\section{Survey}

The students were offered a survey about the FC method. Responding was voluntary and anonymous. They had six weeks to respond to it, between the end of the sessions and the publication of the results of the December exam, including Christmas holydays. The survey is presented in Table 1. The answers were analysed using a descriptive quantitative approach.

\section{Ethics statement}

The study was approved by the School of Medicine of the Universidad de Navarra and by the Ethics Committee for Research of the Universidad de Navarra (project 2018-112). Students were not compensated for their participation in the study. They did not give their informed consent. Data from the students were recorded in a coded database, without personal information.

\section{Statistical analysis}

All data were statistically analysed with the software SPSS version 20. Continuous variables are expressed as mean (standard error of mean) and categorical variables as number (percentage). Groups were compared with the Chi-square test (categorical variables) and Student's $t$ test for independent series (continuous variables), after checking their normal distribution using the Kolmogorov-Smirnov test and their variance homogeneity with the Levene's test. $P$ value below 0.05 was considered statistically significant. In the analysis of factors associated with the improvement of the results after FC, Bonferroni correction was applied; thus, a $\mathrm{P}$ value below 0.017 was considered statistically significant for this analysis. 


\section{Results}

In 2017 and 2018, 229 and 201 students, respectively were enrolled in the pathophysiology course and sat the December exam. Genders and results previously obtained in GP were balanced (Table 2). Most students were 20 years old when starting their third year (i.e. 2017-18 students born in 1997), but some of them were older. The proportion of students older than 20 years was higher in 2018 than in 2017.

\section{Comparison of the results in the control and intervention group.}

The results obtained in the December exam in RP and BP are shown in Table 3. Results improved in RP, but not in BP. The proportion of students that obtained a score above $60 \%$ (the minimum score to pass the December exam) in RP increased from $22 \%$ to $29 \%$ ( $P=0.077)$, and decreased from $33 \%$ to $31 \%$ in $\mathrm{BP}$ $(P=0.757)$.

\section{Effect of the flipped classroom according to academic results, gender and age.}

With the aim of investigating whether the FC method benefits students depending on their academic level, we divided the classes according to their performance in GP in the previous year (above or below the median). The results in BP did not change in 2018, as compared with the results of 2017. After applying the FC, students who scored below the median in GP scored significantly higher in RP (Table 4).

The improvement in the RP results was significant in male students, but not in female students (Table 5). The results of male students in RP in 2018 were significantly better than the results of female students. The two genders did not differ significantly in the other comparisons either in 2017 or in 2018 (Table 6).

Twenty-year-old students, but not older students improved their results in RP significantly after applying the FC (Table 7). The results in BP and in GP did not differ significantly either in younger or in older students. As more older students scored below the median younger students, a post-hoc analysis was performed for students below the median. Twenty-year-old students that scored below the median obtained better results in RP in 2018 than in 2017 (43.3 (0.9) versus 34.3 (1.9); P=0.002), but not in BP or in GP (data not shown). Older students that scored below the median did not obtain significantly different results in BP, RP or GP in 2018 as compared with 2017 (data not shown). The maximum improvement in $\mathrm{RP}$ results was obtained in male, 20-year-old students who scored below the median. Their score improved from 36.8 (2.6) in 2017 to 50.6 (2.9) in 2018 ( $P=0.001)$.

\section{Students' survey}

Twenty students (10\%) responded to the survey about the FC approach (Table 8 ). Eleven (55\%) of them said that it contributed to increasing their interest in the course. Fifteen (75\%) responded that this method helped them to increase their learning gains. Most students expressed that the approach made the topic more easily understandable, but some of them disliked it because it was more time-consuming and necessitated studying the lesson of the day each day. Seventy-five percent of the students wanted to continue learning with this approach, depending on the teacher and the topic. 


\section{Discussion}

The results of this study corroborate other authors' results about the positive effect of FC on medical students' learning, as compared with traditional teaching (7-13). Our results were obtained in a large group with more than 200 learners. A systematic review about this topic included studies with a much smaller sample size(5), whose results have been confirmed in a recently published meta-analysis (3). The FC method of teaching increases active learning (1) and deepens students' understanding (2). Nonetheless, other authors have not found such positive effect on learning (14-16) and a recent metaanalysis in pharmacy education concluded that flipped classroom was associated with minimal gains in student knowledge compared to lecturing (4). This may be due to the different methods of flipped teaching used.

Interestingly, the benefit of FC was not universal. We found that mainly students with scores below the median level of the class improved. This finding is in agreement with the results of Gross et al. (17). This may be due to a higher availability of learning tools or because FC encourages the students to take a more active role in their learning and prepare their classes each day instead of studying just before the exams.

In contrast, older students, most of them below the median, did not improve by applying this active way of learning. We do not think that the age difference is the primary reason for this difference, because most of them were just a year older than their classmates. It seems likely that students with worse results (those who have lost one year or did not pass the course in the previous year) do not improve with FC. It is also likely that FC is not so useful for the improvement of the best students (those above the median), because they are obtaining good results even with a less active way of learning. Thus, it seems that FC is especially useful for those students with results in the mid-low range.

Another interesting finding is the different improvement according to gender. We found a significant improvement with flipped learning only in male students. The results contrast with findings from other studies (17), that showed a more evident improvement in female students. Similarly, female students obtained better academic achievements in an FC undergraduate science course (18). In contrast, Carrick et al. (16) found that women scored higher than men in a traditional classroom environment, but that those differences disappeared in the online classroom. Differences between genders have also been found with the use of other teaching methods, like the writing of multiple-choice questions by the students (19). Likewise, the men and women prefer different teaching materials (20). The differences in the results between genders may be related to the lack of physical interaction between men and women in the online format of the FC, as suggested by Carrick et al. (16) or to being exposed to a broader variety of learning tools, as suggested by Gross et al. (17). Recent studies have found that the learning interests of male and female students differ $(21,22)$.

Another potential benefit of flipped teaching is the improvement of students' attitude. Several authors have found an improvement in this aspect $(13,14,23)$, and the results of our study agree with them. According to the survey, flipped teaching helped our students to be more interested on the topic and to 
increase their knowledge. The only drawback was that some students perceived that this learning methodology increased their time dedicated to study and forced them to study in a day-to-day rhythm. This is consistent with other studies that reported that the students needed more study time with the FC approach (9).

Future studies should investigate whether the FC and its different application methods benefit to students differentially depending on preferred learning styles. A recent study conducted in an FC-based undergraduate science course showed that divergers obtained higher academic achievement than convergers, accommodators and assimilators (18). Future studies should also pay attention to learners' adherence to FC protocols and to the long-term effects of FC with regard to knowledge retention and its transfer to professional practice of medicine (5).

\section{Limitations of the study}

In our study, a single teacher applied the new method in a single university, which may limit the generalizability of the results. Another limitation is the absence of randomization. The results of the intervention group were compared with those obtained in a historic cohort of students. The improvement in the results in the subject given as FC and the lack thereof in the subject taught by traditional didactic lectures suggest that the improvement stems from the new methodology. The study was also limited by the lack of an evaluation of systematic biases, that was not performed because the number of available data was limited. Although limited multiple-choice questions of both exams were new and created by the same teacher with the same criteria of proportion of easy, medium and difficult questions, an imbalance between both exams cannot be ruled out.

The low proportion of respondents to our students survey (10\%) does not allow a firm conclusion about the students' satisfaction with this new method, because a non-response bias cannot be excluded. Another limitation of the survey is that it was not standardised.

Finally, the study is also limited because students did not give informed consent . Our local Institutional Review Board approved the study, the students were informed not only about the introduction of flipped learning, but also about our purpose of analysing its effect on academic performance. Anyway, the analysis of personal data (sex, age and academic performance) without informed consent does not strictly adhere to the European Union General Data Protection Regulation (24).

\section{Conclusions}

The use of flipped learning was followed by an improvement in knowledge acquisition. Male students and those with scores below the median seem to benefit more from this learning method, while those with an academic delay seemed to benefit less from flipped learning.

\section{Abbreviations}


FC: Flipped classroom

RP: Respiratory Pathophysiology

BP: Blood Pathophysiology

GP: General Pathology

\section{Declarations}

\section{Ethics approval and consent to participate}

The study was approved by the School of Medicine of the Universidad de Navarra and by the Ethics Committee for Research of the Universidad de Navarra (project 2018-112).

Students were not compensated for their participation in the study. Some participants responded to a survey. The response was voluntary and anonymous.

\section{Consent for publication}

Not applicable.

\section{Availability of data and materials}

The datasets used and analysed during the current study are available from the corresponding author on reasonable request.

\section{Competing interests}

The authors declare that they have no competing interests.

\section{Funding}

The authors did not receive any funding for this research

\section{Authors' contribution}

Design of the study: JIH and JQ

Preparation of the pedagogical materials for flipped classroom and applying them: JIH

Creation of the database: $\mathrm{JIH}$

Statistical analysis: JIH and JQ

Writing of the manuscript: JIH 
Approval of the final version of the manuscript: JIH and JQ.

\section{Acknowledgements}

Not applicable

\section{References}

1. Jensen JL, Kummer TA, d M Godoy PD. Improvements from a flipped classroom may simply be the fruits of active learning. CBE Life Sci Educ 2015; 14: ar5.

2. McLaughlin JE, Roth MT, Glatt DM, Gharkholonarehe N, Davidson CA, Griffin LM, et al. The flipped classroom: a course redesign to foster learning and engagement in a health professions school. Acad Med 2014; 89:236-43.

3. Hew KF, Lo CK. Flipped classroom improves student learning in health professions education: a meta-analysis. BMC Med Educ 2018; 18: 38.

4. Gillette C, Rudolph M, Kimble C, Rockich-Winston N, Smith L, Broedel-Zaugg K. A meta-analysis of outcomes comparing flipped classroom and lecture. Am J Pharm Educ 2018; 82: 433-40.

5. Chen F, Lui AM, Martinelli SM. A systematic review of the effectiveness of flipped classrooms in medical education. Med Educ 2017; 51: 585-97.

6. Freeman S, Eddy SL, McDonough M, Smith MK, Okoroafor N, Jordt H, Wenderoth MP. Active learning increases student performance in science, engineering and mathematics. Proc Natl Acad Sci U S A 2014; 111: 8410-5.

7. O'Connor EE, Fried J, McNulty N, Shah P, Hogg JP, Lewis P, et al. Flipping Radiology education right side up. Acad Radiol 2016; 23: 810-22.

8. Tune JD, Sturek M, Basile DP. Flipped classroom model imporves graduate student performance in cardiovascular, respiratory and renal physiology. Adv Physiol Educ 2013;37:316-20.

9. Rui Z, Liang-rui X, Rong-zheng Y, Jing Z, Xue-hong W, Chuan Z. Friend or foe? Flipped classroom for undergraduate electrocardiogram learning: a randomized controlled study. BMC Med Educ 2017;17:53.

10. Morton DA, Colbert-Getz JM. Measuring the impact of the flipped anatomy classroom: the importance of categorizing an assessment by Bloom's taxonomy. Anat Sci Educ 2017; 10: 170-5.

11. Lieber CA, Lin DT, Mazer LM, Bereknyei S, Lau JN. Effectiveness of the Surgery core clerckship flipped classroom: a prospective cohort trial. Am J Surg 2016; 211:451-7.

12. Gillispie V. Using the flipped classroom to bridge the gap to generation Y. Oschner J 2016; 16: 32-6.

13. Granero Lucchetti AL, da Silva Ezequiel O, Noceli de Oliveira I, Moreira-Almeida A, Lucchetti A. Using the traditional or flipped classrooms to teach 'Geriatrics and Gerontology'? Investigating the impact of active learning on medical students' competences. Medical Teacher 2018; 40:1248-56.

14. Ilic D, Nordin RB, Glasziou P, Tilson JK, Villanueva E. A randomized controlled trial of a blended learning education intervention for teaching evidence-based medicine. BMC Med Educ 2015;15:39. 
15. Street SE, Gilliland KO, McNeil C, Royal K. The flipped classroom improved medical student performance and satisfaction in a pre-clinical Physiology course. Med Sci Educ 2015; 25:35-43.

16. Carrick FR, Abdulrahman M, Hankir A, Aayruzny M, Najem K, Lungchukiet $P$, et al. Randomized controlled study of a remote flipped classroom Neuro-otology curriculum. Front Neurol 2017; 8: 349.

17. Gross D, Pietri ES, Anderson G, Moyano-Camihort K, Graham MJ. Increased preclass preparation underlies student outcome improvement in the flipped classroom. CBE Life Sci Educ 2015; 14: ar36.

18. Kim M, Roh S, Ihm J. The relationship between non-cognitive student attributes and academic achievements in a flipped learning classroom of a pre-dental science course. Korean J Med Educ 2018; 30: 339-46.

19. Herrero JI, Lucena F, Quiroga J. Randomized study showing the benefit of medical students writing multiple choice questions on their learning. BMC Med Educ 2019; 19: 72.

20. Benditz A, Pulido L, Renkawitz T Schwarz T, Grifk J, Weber M. Are there gender-dependent study habits in times of the world wide web?. Biomed Res Int 2018; 2018: 3196869.

21. Nebeker CA, Basson MD, Haan PS, Davis AT, Ali M, Gupta RN, et al. Do female surgeons learn or teach differently?. Am J Surg 2017; 213:282-7.

22. Ali A, Subhi Y, Ringsted C, Konge L. Gender differences in the acquisition of surgical skills: a systematic review. Surg Endosc 2015; 29: 3065-73.

23. Hsu S-D, Chen C-J, Chang W-K, Hu Y-J. An investigation of the outcomes of PGY students' cognition of and persistent behavior in learning through the intervention of the flipped classroom in Taiwan. PLOS One 2016; 11: e0167598.

24. Regulation (EU) 2016/679 of the European Parliament and of the Council of 27 April 2016 on the protection of natural persons with regard to the processing of personal data and of the free movement of such data, and repealing directive 95/46 EC (General Data Protection Regulation). http://eur-lex-europa.eu/eli/reg/2016/679/oj. Accessed 3 Sept 2019.

\section{Tables}

Table 1. Survey that was sent to the students about the use of flipped classroom in respiratory pathophysiology.

The model of class used for respiratory pathophysiology is more enjoyable than the usual master class

- Completely agree

- Agree

- Neither agree nor disagree

- Disagree

- Completely disagree 
The model of class used for respiratory pathophysiology contributes to the student increasing his/her interest by the subject

- Completely agree

- Agree

- Neither agree nor disagree

- Disagree

- Completely disagree

The model of class used for respiratory pathophysiology contributes to increased learning

- Completely agree

- Agree

- Neither agree nor disagree

- Disagree

- Completely disagree

The model of class used for respiratory pathophysiology decreases the effort of learning

- Completely agree

- Agree

- Neither agree nor disagree

- Disagree

- Completely disagree

Would you like to find this model of class in other subject in the future?

- Yes

- Depending of the subject and the teacher

- Don't care

- No

Do you think the flipped classroom model should replace the use of master class?

- Yes

- Yes, but partially

- Don't care

- No 
Table 2. Baseline comparison of both groups of students.

\begin{tabular}{|c|c|c|c|}
\hline & $\begin{array}{l}2017 \text { (control) } \\
\mathrm{N}=229\end{array}$ & $\begin{array}{l}2018 \text { (intervention**) } \\
\mathrm{N}=201\end{array}$ & $P$ \\
\hline Age & & & 0.043 \\
\hline 20 years & $190(83 \%)$ & $150(75 \%)$ & \\
\hline$>20$ years & 39 (17\%) & 51 (25\%) & \\
\hline Gender & & & 0.156 \\
\hline Male & $73(32 \%)$ & $78(39 \%)$ & \\
\hline Female & $156(68 \%)$ & $123(61 \%)$ & \\
\hline Results in General Pathology* & $58.9(0.9)$ & $59.2(0.9)$ & 0.830 \\
\hline
\end{tabular}

Comparisons between groups were done with the Chi-square test (categorical variables) and Student's t test (continuous variables).

$\mathrm{P}<0.05$ was considered statistically significant.

Results are expressed as mean (standard error of mean) or number (percentage).

* out of $100(\mathrm{~N}=218$ in 2017 and 176 in 2018)

**Intervention: Flipped classroom in Respiratory Pathophysiology.

Table 3. Comparison of the results obtained in respiratory and blood pathophysiology in the control and the intervention group*.

\begin{tabular}{|l|l|l|l|}
\hline & 2017 (control) & 2018 (intervention**) & $\mathrm{P}$ \\
& $\mathrm{N}=229$ & $\mathrm{~N}=201$ & \\
\hline Blood Pathophysiology & $48.8(1.4)$ & $47.9(1.4)$ & 0.649 \\
\hline Respiratory Pathophysiology & $42.1(1.4)$ & $48(1.5)$ & 0.004 \\
\hline
\end{tabular}

Groups were compared with the Student's t test.

$\mathrm{P}<0.05$ was considered statistically significant. 
Results are expressed as mean (standard error of mean).

*out of 100

**Intervention: Flipped classroom in Respiratory Pathophysiology.

Table 4. Evaluation of the impact of flipped classroom in respiratory pathophysiology teaching in students above and below the median in general pathology*.

\begin{tabular}{|l|l|l|l|}
\hline & $\begin{array}{l}2017 \text { (control) } \\
\mathrm{N}=229\end{array}$ & $\mathrm{~N}=2018$ (intervention**) & $\mathrm{P}$ \\
Blood Pathophysiology & & & \\
Above median & & & 0.647 \\
\hline Respiratory Pathophysiology & $59.4(1.8)$ & $38.2(2.0)$ & 0.573 \\
\hline Below median & & $58.1(1.8)$ & \\
Above median & $32.9(1.7)$ & $39.8(1.9)$ & 0.009 \\
& $53.5(1.9)$ & $57.2(2.2)$ & 0.200 \\
\hline
\end{tabular}

Groups were compared with the Student's t test.

$\mathrm{P}<0.017$ was considered statistically significant.

Results are expressed as mean (standard error of mean).

*out of 100. Median score in General Pathology was 59 in 2017 and 60 in 2018.

**Intervention: Flipped classroom in Respiratory Pathophysiology.

Table 5. Evaluation of the impact of flipped classroom in the teaching of respiratory pathophysiology according to gender*. 


\begin{tabular}{|l|l|l|l|}
\hline & N=229 & $\mathrm{N}=201$ & \\
Male & & & \\
Female & $52.0(2.3)$ & $48.7(2.1)$ & 0.301 \\
Blood Pathophysiology & $47.4(1.7)$ & $47.5(1.9)$ & 0.981 \\
\hline Mespiratory Pathophysiology & & & 0.010 \\
\hline
\end{tabular}

Groups were compared with the Student's t test.

$\mathrm{P}<0.017$ was considered statistically significant.

Results are expressed as mean (standard error of mean).

*out of 100

**Intervention: Flipped classroom in Respiratory Pathophysiology.

Table 6. Comparison of the academic results between male and female students.* 


\begin{tabular}{|l|l|l|l|}
\hline & Male & Female & $\mathrm{P}$ \\
\hline Ge17 (control) & $\mathrm{N}=73$ & $\mathrm{~N}=156$ & \\
Blood & $58.3(1.7)$ & $59.2(1.0)$ & 0.638 \\
Respiratory & $52.0(2.3)$ & $47.4(1.7)$ & 0.131 \\
\hline 2018 (intervention**) & N=78 & $\mathrm{N}=123$ & \\
General Pathology & & & \\
Blood & $59.9(1.5)$ & $58.7(1.2)$ & 0.534 \\
Respiratory & $48.7(2.1)$ & $47.5(1.9)$ & 0.670 \\
& $52.5(2.1)$ & $45.1(2.0)$ & 0.014 \\
\hline
\end{tabular}

Groups were compared with the Student's t test.

$\mathrm{P}<0.017$ was considered statistically significant.

Results are expressed as mean (standard error of mean).

*out of 100

**Intervention: Flipped classroom in Respiratory Pathophysiology.

Table 7. Evolution of academic results* according to age after applying the flipped classroom method in respiratory pathophysiology in 2018. 


\begin{tabular}{|l|l|l|l|}
\hline & 2017 (control) & 2018 (intervention**) & $\mathrm{P}$ \\
\hline 20-year-old & $\mathrm{N}=39$ & $\mathrm{~N}=51$ & \\
General Pathology & $60.0(0.9)$ & $60.6(1.0)$ & 0.665 \\
Blood Pathophysiology & $50.2(1.6)$ & $49.8(1.6)$ & 0.888 \\
Respiratory Pathophysiology & $44.1(1.5)$ & $51.1(1.6)$ & 0.002 \\
\hline Older students & $\mathrm{N}=179$ & $\mathrm{~N}=150$ & \\
General Pathology & $52.6(2.6)$ & $53.5(2.4)$ & 0.789 \\
Blood Pathophysiology & $42.5(3.0)$ & $42.4(2.7)$ & 0.973 \\
Respiratory Pathophysiology & $32.5(3.1)$ & $38.9(2.9)$ & 0.142 \\
\hline
\end{tabular}

Groups were compared with the Student's t test.

$\mathrm{P}<0.017$ was considered statistically significant.

Results are expressed as mean (standard error of mean).

*out of 100

**Intervention: Flipped classroom in Respiratory Pathophysiology.

Table 8. Results of the survey about the flipped learning (20 respondents).

\begin{tabular}{|l|l|l|l|}
\hline & Agree & $\begin{array}{l}\text { Neither agree nor } \\
\text { disagree }\end{array}$ & Disagree \\
\hline Flipped method is more enjoyable & $\begin{array}{l}12 \\
(60 \%)\end{array}$ & $7(35 \%)$ & $1(5 \%)$ \\
\hline Flipped method increases interest & $\begin{array}{l}11 \\
(55 \%)\end{array}$ & $7(35 \%)$ & $2(10 \%)$ \\
\hline Flipped method increases learning & $\begin{array}{l}15 \\
(75 \%)\end{array}$ & $5(25 \%)$ & $0(0 \%)$ \\
\hline $\begin{array}{l}\text { Flipped method decreases the effort of } \\
\text { learning }\end{array}$ & $\begin{array}{l}14 \\
(70 \%)\end{array}$ & $4(20 \%)$ & $2(10 \%)$ \\
\hline $\begin{array}{l}\text { Flipped method should substitute lectures } \\
\text { (partially or totally) }\end{array}$ & $\begin{array}{l}15 \\
(75 \%)\end{array}$ & $0(0 \%)$ & $5(25 \%)$ \\
\hline
\end{tabular}

